\title{
Adolescent Drug Use in Connecticut Private High Schools: Zero Tolerance, Contextual Peer Influence, and Deterrence Effectiveness
}

\author{
Minjune Song ${ }^{1}$ \\ ${ }^{1}$ Independent Scholar, Connecticut, USA \\ Correspondence: Minjune Song, Independent Scholar, Connecticut, USA. E-mail: mjsong2021@gmail.com
}

Received: August 6, 2020 Accepted: September 17, 2020 Online Published: September 27, 2020

doi:10.5539/jel.v9n5p256 URL: https://doi.org/10.5539/jel.v9n5p256

\begin{abstract}
After the 1994 Gun-Free School Act, schools expanded the use of zero-tolerance policies with all Connecticut private high schools implementing punitive drug and alcohol policies. Based on the criminological theory of deterrence, zero-tolerance policies deliver severe and certain punishments designed to deter rational actors from engaging in problem behaviors. Existing research suggests that adolescents perceive rewards more strongly around peers and lack impulse control, raising the possibility that peer pressure may override rational deterrence in an adolescents' decision-making process. An "immune group" of adolescents predisposed to ignore punitive deterrents may play a sizable role in inducing peer drug use. If peer influence supersedes deterrence in a significant number of cases, adolescents who are affected both by deterrents and peer pressure may be at a higher risk of following the example of the "immune group." This study raises the question of whether Connecticut private high school students' drug use is correlated with perceptions of punishment mandated by school policy and contextual peer influences. A questionnaire that measured students' drug use on a scale of 1 to 4 , perceived severity and likelihood of punishment from 0 to 10 , and interaction with drug using peers from 0 to 10 , was completed by 50 respondents. The study found no correlations between student drug use and perception of punishment likelihood and severity but found contextual peer influences to be positively associated with expected student drug use in the future. While the results of this study are limited to Connecticut private high school students, the observed tendency in students to disregard risks and pursue peer-involved drug use may be generalized in adolescents. Even in places where school discipline is not a wide issue, the impact of contextual factors like peer influence must be reconceptualized in thinking about school drug policies.
\end{abstract}

Keywords: adolescent drug use, school discipline, peer pressure, punishment effectiveness, deterrence theory, zero tolerance

\section{Introduction}

Criminological deterrence, the concept of deterring criminals and non-criminals from committing crimes, is a central concept in the criminal justice system. Deterrence theory also has a place in school discipline, notably in the form of school zero-tolerance policies. In general, zero-tolerance policies prohibit people in authority from exercising discretion on a case-by-case basis, instead mandating severe and certain punishments regardless of individual circumstances. Recent research on the negative consequences of zero-tolerance policies has caused the media and the federal government to regard zero tolerance in an increasingly critical light. A 2008 Zero Tolerance Task Force report by the American Psychological Association (APA) indicates that the use of zero-tolerance policies often fails to improve school discipline and is instead associated with higher rates of school dropout and failure to graduate (APA Zero Tolerance Task Force, 2008). In addition, the 2014 the U.S. Department of Education and Department of Justice Civil Rights Data Collection briefing encourages educators to reduce their reliance on zero-tolerance punishments like suspensions and expulsions when creating safer learning environments (U.S. Department of Education Office for Civil Rights, 2014). In the era of heightened educator accountability, it is appropriate to thoroughly evaluate whether zero tolerance policies indeed contribute to furthering educational goals. This paper extends the debate on zero-tolerance policy by examining the relationship between zero tolerance policies and student drug use in three different peer contexts.

The punitive and exclusionary nature of zero-tolerance policies has been linked to detrimental consequences for punished students. Recent research has found that zero-tolerance policies result in the suspension of Black students at three times the rate of White students (U.S. Department of Education Office for Civil Rights, 2014). At least one 
study provides evidence that zero tolerance aggravates already existing racial inequalities in rates of student suspension and expulsion (Hoffman, 2014). In the field of exclusionary discipline, studies have found the rates of suspensions and expulsions to be closely correlated with increased delinquency, lower academic achievement, and higher school dropout rates (Raffaele Mendez, 2003; Martinez, 2009). While research so far has clearly demonstrated the negative outcomes of zero-tolerance policies' exclusionary nature, relatively little research evaluates the deterrence effect (if any) of such policies.

Studies so far have found drug use to be a sizable contributor to student suspension: nearly $15 \%$ of all suspensions are a result of illegal drug abuse. Despite nearly $98 \%$ of schools nationwide having written drug and alcohol policies, only a small number of studies measure the effectiveness of school zero-tolerance policy in deterring collective student drug use (APA Zero Tolerance Task Force, 2008; Curran, 2016). If indeed zero tolerance generally deters students from using drugs, the harms of zero-tolerance policies may be offset by their overall benefits.

However, emerging research on adolescent brain function and social behavior offer results that are contradictory to the core philosophy of zero tolerance. Under the bioecological model, adolescents perceive rewards more strongly around peers and lack impulse control because of changes in the brain's maturation process (Bronfenbrenner \& Morris, 2006; Steinberg, 2008). Studies have also shown that adolescents in tight, intimate peer groups are more likely to hold delinquent views at odds with social norms. It has been well established that peer pressure has a strong influence over adolescents, in general surpassing parental moderation (Dorius et al., 2004). Peer interaction is an everyday occurrence for adolescents both in and out of school. The effectiveness of zero tolerance cannot be accurately measured without considering the contextual factor of the peer influence that is so highly prevalent in real-world scenarios. Steinberg's findings on adolescent behavior especially suggest the possibility that adolescents may prioritize rewards from peer interactions over a punishment deterrent in decision making. Under these frameworks, zero-tolerance policy and its deterring effects may not apply to adolescent age groups.

Fundamentally, this study aims to assess the influence that the severity and likelihood of punishment in zero-tolerance policies have on licit and illicit adolescent drug use. The study addresses two questions: 1) Does a correlation between student drug use and punishment severity and likelihood exist? and 2) Do contextual factors like peer influence have a stronger correlation with adolescent drug use compared to zero-tolerance policies. This study aims to lay the groundwork for future research by juxtaposing the deterrence effects of zero-tolerance policies with the influence of a contextual factor on adolescent drug abuse, challenging researchers and educators to reconceptualize the reaches of peer influence and the limits of punitive and exclusionary discipline.

\section{Literature Review}

\subsection{Adolescent Drug Abuse}

Adolescent drug abuse remains a deeply ingrained problem in schools and communities nationwide. National use of tobacco, alcohol, marijuana, and other illicit drugs have stabilized and are on a downward trend, but new emergencies like vapable nicotine and marijuana gained significant traction among adolescents. $35.7 \%$ of 12 th graders, $28.8 \%$ of 10 th graders, and $11.8 \%$ of eighth graders are reported having used marijuana in the past year (U.S. Department of Health and Human Services, 2019). The use of regular cigarettes has continued to decline, with $5.7 \%$ of adolescents reporting using cigarettes regularly compared to $7.6 \%$ and $13.6 \%$ in 2017 and 2014 , respectively. Vaping products, however, have gained alarming popularity, appearing to replace traditional tobacco products for a younger audience. One in four 12 th graders has reported vaping nicotine in the past month, and $8.1 \%$ of 12 th graders noted that they vaped because they are "hooked". In 2018, only 3.6\% of adolescents vaped because they were addicted to nicotine (U.S. Department of Health and Human Services, 2019).

The growing prevalence of adolescent vaping poses a formidable threat to public health and educational performance given that early and frequent substance use in adolescents predicts lower academic achievement, lower engagement in school, and earlier contact with the criminal justice system. In a study of Canadian youth, the rates of tobacco, alcohol, and marijuana use were found to be strongly associated with proximity measures that predicted poor education (Pathammavong et al., 2011). Research has also shown adolescent drug use to be associated with truancy, a precursor to delinquency (Ellickson et al., 2004). Research has also shown student academic performance in school to be strongly negatively linked with marijuana use. When ranked from highest academic achievement to lowest academic achievement, students who did not use marijuana ranked the highest and students who used marijuana both regularly and in school ranked the lowest (Finn, 2012).

In addition, adolescent drug abuse disproportionately affects youth in areas marked by underemployment and non-traditional family structures. Past research has found that high poverty and high unemployment were community indicators strongly associated with higher adolescent drug use (Hoffman, 2002). Areas afflicted with 
poverty and unemployment may be unable to organize and influence the behavior of their residents, failing to prevent adolescent drug use at the community level (Elliott et al., 1996). Children from single-parent families and stepparent families used drugs at a significantly higher rate than children from families with both a biological mother and a biological father, implying that children from non-mother-family structures may lack the necessary parental support at home (Hoffman, 2002). Evidence from studies on a smaller scale also suggests adolescents marginalized from school or society often use drugs as part of their counter-school identity (Fletcher et al., 2009). One study raises the point that adolescent drug abuse may take the form of creative resistance, in this case in the form of "mellow resistance" against a confirmative school environment (Fletcher et al., 2009). Concerns that adolescent drug abuse stems from deeper systemic inequalities like race or social class exist, and there is consensus in research that structural change in school and the broader society must take place to create an environment more conducive to high performance for all students.

\subsection{Exclusionary Discipline}

In schools, exclusionary discipline is a type of severe discipline that punishes students by excluding them from school grounds. Exclusionary discipline takes two forms: suspensions, and expulsions. While length of exclusion may vary by school, a "suspension" generally refers to a shorter period of exclusion (within ten days), while an "expulsion" refers to a longer period of exclusion that may span the semester or the academic year. Evidence shows that the use of exclusionary discipline for students increases as they progress from grade to grade, peaking at around age 15 (Arcia, 2006). While research finds that suspensions do not diminish student misbehavior (Raffaele, 2003), increased suspensions are strongly correlated with lower academic achievement (Arcia, 2006). Furthermore, the suspension rates in students have also been correlated with earlier encounters with the juvenile justice system (Costenbader \& Markson, 1998). Past research focuses more on the immediate association between suspension and problem behaviors, often failing to identify a causal relationship. Previous research has also been limited in that it often does not explicitly evaluate the role that school exclusionary policies play in overall student misbehavior. As exclusionary discipline is widely applied in school policies like zero tolerance, studying the effects of exclusionary discipline on general misbehavior levels would be significant given how widely such discipline is implemented.

\subsection{Zero-Tolerance Policy}

Zero-tolerance policies entered schools in the United States in 1994 when the Guns Free School Act (GFSA) mandated that states receiving federal funding implement state laws that required the year-long exclusion of any students who brought a firearm onto school grounds. In the 21 st century, nearly all schools embraced the federal initiative by adopting a zero-tolerance policy for major infractions beyond firearm offenses. Principles nationwide defined zero-tolerance policy as "a school or district policy that mandates predetermined consequences or punishments for specific offenses" (U.S. Commissioner of Education Statistics, 1998). The OCR defines zero-tolerance policies as follows (APA Zero Tolerance Task Force, 2008):

[a] commonly accepted definition of a 'zero-tolerance policy' is one that 'mandates the application of predetermined consequences, most often severe and punitive in nature, that are intended to be applied regardless of the gravity of behavior, mitigating circumstances, or situational context'.

The 2008 APA Zero Tolerance Task Force notes there is a significant lack of research focusing explicitly on zero-tolerance policy and its effects on overall student misbehavior (APA Zero Tolerance Task Force, 2008). Curran's study that focus on zero-tolerance policies find little to no change in principal perceptions of problems (an increase in problem perception for assault) after conducting a longitudinal study of problem perceptions before and after the passing of the GFSA (Curran, 2016).

Despite existing literature criticizing the use of exclusionary policies like zero tolerance (Morrison \& Skiba, 2001; Maag, 2001), the 1996 National Center for Education Statistics report found 87 to $88 \%$ of principals nationwide to have put zero tolerance policies in place for alcohol and drug use, respectively (U.S. Commissioner of Education Statistics, 1998). Adolescent drug abuse is a multi-faceted problem that stretches beyond school policy and impacts other stakeholders like the administration, students, and the wider community. While much academic literature condemns zero tolerance and exclusions for alienating students and aggravating delinquent behavior, suspensions and expulsions packaged into zero-tolerance policy remain the favorite "treatment" for adolescent drug abuse (U.S. Commissioner of Education Statistics, 1998). Zero tolerance as studied in this paper refers exclusively to school zero-tolerance policies. While zero tolerance often has associations with severe or confirmative school environments that take a zero-tolerance approach, this study limits itself to zero-tolerance policies per se and their effectiveness reducing drug use in relation to peer context factors. 


\subsection{Competing Theories on Zero Tolerance}

Two competing theories prominent in the relevant academic literature, the theory of deterrence and the theory of adolescent risk-taking, serve as the framework and basis of this study. The criminological theory of deterrence is the theoretical foundation of zero-tolerance policies. The principles of deterrence theory rest on a set of presumptions that humans act based on decisions that hold the greatest advantage of benefits to cost (Bentham et al., 1982; Zimring \& Hawkins, 1976). In deterrence theory, humans are rational enough to consider the outcomes of their actions and will be influenced by those outcomes when making decisions (Kennedy, 2010). The principles of deterrence theory state that humans are self-interested, rational, and reasoning. Several hypotheses on deterrence theory have been offered based on these presumptions (Gibbs, 1968):

1) The greater the certainty of legal punishment, the lower the crime rate.

2) The greater the severity of legal punishment, the lower the crime rate.

3) The greater the celebrity of legal punishment, the lower the crime rate.

The certainty and severity of punishments following an infraction are factors believed to prevent people from committing crimes, and laws more strongly associated with the three factors above are believed to output a lower crime rate (Beccaria, 2009; Nagin, 1998). Deterrence theory has had some effect in deterring youths in the juvenile justice system from committing crimes (Pauwels et al., 2011), while its effect on school misbehavior have been less studied.

Alternatively, the adolescent risk-taking theory used in this study draws from social behavioral and neurobiological research that considers adolescent behavioral outcomes in the context of characteristics of the maturing adolescent brain. Social behavioral studies, in turn, draw work from bioecological theory and social learning theory. Bioecological theory suggests that adolescents are influenced strongly by contextual factors surrounding their development (Bronfenbrenner \& Morris, 2006), while social learning theory maintains that deviant impulse are inherent in adolescents: social controls from family or other social institutions act to stop adolescents from acting on deviant impulses (Hirschi, 1969). Studies following the social learning framework found intimate and small peer group environments to allow adolescents to observe, participate, and reinforce deviant behaviors, including drug use (Reed \& Roundtree, 1997).

In studies that utilized neuro scanning to study adolescent risk-taking, evidence suggests that neurobiological characteristics of the adolescents are correlated with an inordinate focus on rewards rather than consequence of actions (Gardner \& Steinberg, 2005). Steinberg suggests that neurological changes in dopamine pathways and oxytocin receptors act to heighten adolescents' desire for rewards in the presence of peers (Steinberg, 2008). In addition, Steinberg (2008) also demonstrates that adolescents lack well-developed impulsive behavior control functions in the prefrontal cortex, an underdevelopment that may contribute to their disproportionate focus on rewards. Evidence also suggests that through positive experiences of peer-involved marijuana use, adolescents develop positive cognitive associations with the use of marijuana, expecting similar positive social responses when they use marijuana in the future (Petraitis et al., 1995).

While evidence suggests that adolescents are capable of rational thinking not unlike that of adults, the competing theories about adolescent risk-taking seem to suggest peer influence may warp decision-making at the fundamental levels of the adolescent brain. In a realistic school environment where adolescents interact robustly with peers in and out of classrooms, the theory of deterrence may not hold.

\section{Results}

\subsection{Subsection A: Methods}

\subsubsection{Data Sample}

Data for the analysis were obtained through an online survey distributed to high school students via email. Students completed a 15-question questionnaire regarding their drug use and their perceptions of school drug and alcohol policy; their names remained anonymous to encourage honest responses. Of the 54 student respondents, 50 attended a high school in Connecticut in the 2019-2020 school year.

Out of 50 respondents, 22 respondents were 11th graders (juniors), 13 were 10th graders (sophomores), 10 were 9th graders (freshmen), and 5 were 12th graders (seniors). 35 students (69.2\%) were boarding students who lived on-campus during the school year, while 15 students were day students who did not live on campus.

Connecticut is a state with the second highest per capita income in the U.S. (U.S. Census Bureau, 2010-2014), and a state particularly renowned for its abundance of private schools, and for having the third highest educational performance in the nation (Education Week, 2018). Past research has shown that children from families with 
higher disposable incomes, and children attending more conformist and academically intensive schools, are often more prone to drug abuse (Luthar et al., 2018). Due to the dominance of boarding school students in the sample, this study hypothesized that the conflict between peer influence and school policy would be prominently displayed in the results

\subsubsection{Measure: Rates of Drug Use}

Students answered a total of four drug use questions, two on licit drug use (any form of tobacco/nicotine use, alcohol, non-prescribed prescription drugs, inhalants/hallucinogens purchased legally), and two on illicit drug use (non-prescribed marijuana, LSD/mushrooms, any form of opiates, cocaine, MDMA variants, other substances illegal in the state of Connecticut) on a past school month and on a projected future school month. Expected drug use was measured by asking students what their expected rate of licit/illicit drug use would be in a future school month. For all questions, students were asked to rate their drug use on a scale of 0 to $4(0=$ none, $1=$ once a month or less, 2 = two to four times a month, $3=$ two to three times a week, 4 = four times a week or more).

\subsubsection{Measure: Peer Influence}

This study posed questions to specifically measure the effect peer contexts had on student drug use. The degree of influence peers had on students in each peer context was measured by three aspects: proportion of student's friends who approved of drug use; proportion of student's friends who regularly used drugs; proportion of student's time spent around friends who regularly used drugs.

To measure what proportion of respondent's friends approved of drug use, students were asked to rate their friends' approval of drug use on a scale of 0 to $10(0=$ none, $1-2=$ almost none, $3-4=$ fewer than half, $5=$ half of them, $6-7=$ more than half, $8-9=$ nearly all, $10=$ all). To measure what proportion of a respondent's friends used drugs, students were asked to indicate the proportion of his or her friends who regularly used drugs on a scale of 0 to 10 ( 0 $=$ none, $1-2=$ almost none, $3-4=$ fewer than half, $5=$ half of them, $6-7=$ more than half, $8-9=$ nearly all, $10=$ all). To measure how much time students spent around friends who used drugs, students were asked to report the proportion of free time that they spent around friends who regularly used drugs on a scale of 0 to $10(0=$ none, $1-2$ $=$ almost none, $3-4=$ fewer than half, $5=$ half, $6-7=$ more than half, $8-9=$ nearly all, $10=$ all).

\subsubsection{Measure: Perceived Punishment of Policy}

Under the principles of criminological deterrence theory, three hypotheses exist: the greater the certainty of punishment, the lower the crime rate; the greater the severity of punishment, the lower the crime rate; the greater the swiftness of punishment, the lower the crime rate. Questions were accordingly devised to measure student perceptions of punishment severity and punishment likelihood for breaking a school drug and alcohol policy. Swiftness of policy delivery is not explicitly specified by schools unlike punishment severity, nor can students gauge the celebrity of punishments unless they have been punished: thus, this study does not measure student perception of punishment swiftness. By quantifying how students perceive the school policy, this study aims to see if the "crime rate" (student drug use) is dependent on student perceptions of punishment severity and likelihood.

To measure the severity of drug and alcohol policy punishments, students were asked to rate their perceived severity of punishment consequences on a scale of 0 to $10(0=$ no punishment, $1-2=$ not severe enough, $3-4=$ not on the severe side, $5=$ just right, $6-7=$ on the severe side, $8-9=$ more severe than necessary, $10=$ extremely severe). Student perceptions of punishment severity are not objective: therefore, broad definitions reflecting how students personally feel about the punishment were used to measure severity. To measure the likelihood of receiving a punishment, students were asked to rate the perceived risk of getting caught using drugs at school on a scale of 0 to $10(0=$ no risk of getting caught, $1-2=$ minimal risk of getting caught, $3-4=$ not likely to be caught, $5=$ fifty/fifty risk of getting caught, $6-7=$ likely to be caught, $8-9=$ very high risk of getting caught, $10=$ certainly caught). It is important to measure certainty with respect to the perceived risk of getting caught: if students perceive punishments to be severe but chances of detection to be low, the zero-tolerance policy may not deter students from using drugs. 


\subsection{Subsection B: Results}

Table 1. Expected frequency of past and licit and illicit drug use

\begin{tabular}{llllllllll}
\hline & \multicolumn{1}{l}{ Past Use } & \multicolumn{7}{l}{ Expected Use } \\
\cline { 2 - 9 } Variable & \multicolumn{2}{l}{ Licit } & Illicit & \multicolumn{2}{l}{ Licit } & Illicit \\
\cline { 2 - 9 } & $\mathrm{n}$ & $\%(n=50)$ & $\mathrm{n}$ & $\%(n=50)$ & $\mathrm{n}$ & $\begin{array}{l}\% \text { change from past } \\
(n=50)\end{array}$ & $\mathrm{n}$ & $\begin{array}{l}\text { \% change from past } \\
(n=50)\end{array}$ \\
\hline None & 21 & 42 & 23 & 46 & 16 & -10 & 19 & -8 \\
once a month or less & 6 & 12 & 8 & 16 & 10 & +8 & 10 & +4 \\
2-4 times a month & 6 & 12 & 3 & 6 & 8 & +4 & 7 & +8 \\
2-3 times a week & 5 & 10 & 5 & 10 & 6 & +2 & 6 & +2 \\
4 or more times a week & 12 & 24 & 11 & 22 & 10 & -4 & 8 & -6 \\
\hline
\end{tabular}

Licit and illicit adolescent drug use varied widely by age and by boarding status, affirming trends in national surveys where adolescent drug use increased along grade lines and peaked among 11 th and 12 th graders. Around $90 \%$ of freshmen students did not use licit or illicit drugs four or more times in one week (heavily), and $40 \%$ of freshmen did not use any licit or illicit drugs. Sophomores had higher rates of drug usage, yet $61.5 \%$ of sophomores did not use any drugs in school months: $15.4 \%$ used both licit and illicit drugs heavily. By contrast, juniors and seniors had high concentrations of students who used drugs heavily. Only about one fifth of junior and senior respondents said they did not use both licit and illicit drugs in a past school month. Less than half, $40.7 \%$, of juniors and seniors used either a licit or illicit drug heavily. Among this age group, there were more respondents who used both licit and illicit drugs heavily (25.9\%), than those who did not use drugs at all.

A divisive contrast in drug use between students who live on campus (boarding students) and students who live at home (day students) indicates that adolescents living on campus use drugs more frequently. $20 \%$ of day students did not use both licit and illicit drugs, and none used both licit and illicit drugs heavily. On the other hand, only 1 in 8 boarding juniors did not use either a licit or an illicit drug during school months. Being a freshman or sophomore boarding student meant most would not use licit or illicit drugs at all: out of the 14 boarding students who did not use both licit and illicit drugs, 11 were of freshman or sophomores. Of the total 9 respondents out of 50 who used both licit and illicit drugs heavily, 7 were boarding juniors.

\subsubsection{Major Trends 1}

In this section, two hypotheses were proposed to explain major correlations between the expected frequency of licit and illicit drug use and the three peer context factors. In Table 1, drug use trends from past use to expected use indicate a shift in students who previously used little or no drugs expecting to increase their frequency of drug use. In accordance with this study's goal to identify how school policy punishment severity and likelihood and peer context factors influence student drug use, expected drug use results will be utilized as an independent variable for Tables 2, 3, 4, and 5 to measure the effect variables have in determining future adolescent drug use patterns.

Hypothesis:

- The hypothesis states there will be a positive correlation between the frequency of licit and illicit student drug use and peer context factors. The hypothesis will stand if peer context factors increase with student drug use frequency. The hypothesis follows the general presumption that adolescents value their social standing among peers strongly and that peer context factors will override deterrence from adults and school. Major findings from literature that may support the hypothesis are as follows: adolescents who use drugs socially develop positive cognitive definitions of drug use; adolescents in intimate peer groups develop deviant behaviors like drug use via observation, practice, and reinforcement; adolescents disproportionately focus on rewards rather than risks in the presence of peers; adolescent brains lack impulsive control functions.

Null hypothesis:

- The null hypothesis states that there will be a negative correlation between the frequency of licit and illicit student drug use and peer context factors. If peer influence decreases when frequency of drug use increases, the null hypothesis will be true. If found to be true, the null hypothesis would contradict the findings of a large body of literature that estimate peer influence to significantly affect adolescent drug use. Significant evidence from the literature supporting the null hypothesis may be summarized as follows: adolescents possess a capacity to think rationally equal to adults and will be deterred by severe 
and certain policies with similar effect; as high parental monitoring is found to counter peer influences promoting drug use, high school monitoring can achieve effects similar to those of peer influence. Furthermore, there is also the possibility that findings supporting the hypothesis are lacking in scope and do not apply to this sample.

Table 2. Correlation between licit drug use and peer context factors

\begin{tabular}{|c|c|c|c|c|c|}
\hline \multirow[b]{2}{*}{ Expected Use } & \multicolumn{5}{|c|}{ Proportion of Friends Who Regularly Use Drugs $(0-10)$} \\
\hline & 0 & $1-3$ & $4-6$ & $7-9$ & 10 \\
\hline \multicolumn{6}{|l|}{$\%$ distribution } \\
\hline None $(n=16)$ & 25 & 50 & 18.8 & 6.3 & \\
\hline Once a month or less $(n=10)$ & & & 30 & 60 & 10 \\
\hline $2-4$ times a month $(n=8)$ & & 25 & 25 & 50 & \\
\hline $2-3$ times a week $(n=6)$ & & & 16.7 & 83.3 & \\
\hline \multirow[t]{3}{*}{4 times a week or more $(n=10)$} & & & 10 & 70 & 20 \\
\hline & \multicolumn{5}{|c|}{ Proportion of Friends Who Approve Drug Use $(0-10)$} \\
\hline & 0 & $1-3$ & $4-6$ & $7-9$ & 10 \\
\hline \multicolumn{6}{|l|}{$\%$ distribution } \\
\hline None & 6.25 & 25 & 56.25 & 12.5 & \\
\hline Once a month or less & & & 10 & 40 & 50 \\
\hline 2-4 times a month & & & 50 & 25 & 25 \\
\hline $2-3$ times a week & & & & 83.3 & 16.7 \\
\hline \multirow{3}{*}{4 times a week or more } & & & & 60 & 40 \\
\hline & \multicolumn{5}{|c|}{ Proportion of Free Time Spent with Peers Who Regularly Use Drugs $(0-10)$} \\
\hline & 0 & $1-3$ & $4-6$ & $7-9$ & 10 \\
\hline \multicolumn{6}{|l|}{$\%$ distribution } \\
\hline None & 25 & 56.25 & 18.75 & & \\
\hline Once a month or less & & 20 & 20 & 50 & 10 \\
\hline $2-4$ times a month & & 50 & 12.5 & 25 & 12.5 \\
\hline 2-3 times a week & & 16.7 & 33.3 & 50 & \\
\hline 4 times a week or more & & & & 60 & 40 \\
\hline
\end{tabular}

In Table 2, a moderate to strong positive correlation was found linking the frequency of licit student drug use and the three peer context factors. A statistically significant, moderate positive correlation existed between the expected frequency of licit drug use and the proportion of friends who approved of drug use, $r(50)=.529, p<.001$. No respondents stated that all their friends disapproved of drug use. Students who expected not to use any licit drugs were split between having almost no friends who approved of drug use $(31.25 \%)$ and having half or more than half of their friends approve of drug use (68.75\%). Compared to other groups, students who expected not to use licit drugs were more likely to have none, almost none, or fewer than half of their friends approve of drug use. Also, students who expected to use licit drugs, regardless of frequency, did not have friends who nearly all or all disapproved of drug use.

A statistically significant, moderate positive correlation was found between the expected frequency of licit drug use and the proportion of friends who regularly used drugs, $\mathrm{r}(50)=.629, \mathrm{p}<.001$. All students who did not expect to use licit drugs said that none of their friends regularly used drugs, but a small fraction (6\%) of them said nearly all their friends regularly used drugs. Students who did not have peers who regularly used drugs as friends could be found only in respondents who expected not to use licit drugs $(25 \%)$. In contrast, none of the students who expected to use licit drugs 2-3 times a week, or 4 times a week or more, had friends all of whom did not regularly use drugs.

Finally, a statistically significant, strong positive correlation existed between the expected frequency of licit drug use and the proportion of free time spent around friends who regularly used drugs, $r(50)=.718, p<.001$. Students who expected to use licit drugs 4 times a week or more almost exclusively spent their free time around peers who regularly used drugs: $60 \%$ more than half to nearly all, $40 \%$ all. More than half of those who did not expect to use licit drugs spent almost none of their free time around peers who regularly used drugs $(56.25 \%)$, and a quarter never spent time around peers who regularly used drugs. The pattern of spending more time around drug-using peers the more frequently one expected to use drugs was evident among students who expected to use drugs once a month, 2-4 times a week, or 2-3 times a week. Nevertheless, only a fraction of these students extended to either extremes of spending almost no time around drug-using peers or spending all their free time around drug-using 
peers.

The observed trends in Table 2, both positive and statistically significant, contradict the null hypothesis. There was a moderate to strong positive correlation between peer context factors and expected licit drug use. Results from Table 2 support the hypothesis, showing a statistically significant positive correlation between an increase in peer context factors and a decrease in expected licit drug use across the board.

Table 3. Correlation between expected frequency of illicit drug use and peer context tactors

\begin{tabular}{|c|c|c|c|c|c|}
\hline \multirow[b]{2}{*}{ Expected Use } & \multicolumn{5}{|c|}{ Proportion of Friends Who Regularly Use Drugs $(0-10)$} \\
\hline & 0 & $1-3$ & $4-6$ & $7-9$ & 10 \\
\hline \multicolumn{6}{|l|}{$\%$ distribution } \\
\hline None $(n=19)$ & 21.05 & 42.11 & 21.05 & 15.79 & \\
\hline Once a month or less $(n=10)$ & & 10 & 20 & 70 & \\
\hline $2-4$ times a month $(n=7)$ & & 14.29 & 28.57 & 57.14 & \\
\hline $2-3$ times a week $(n=6)$ & & & 16.67 & 66.67 & 16.67 \\
\hline \multirow[t]{3}{*}{4 times a week or more $(n=8)$} & & & 12.5 & 62.5 & 25 \\
\hline & \multicolumn{5}{|c|}{ Proportion of Friends Who Approve Drug Use (0-10) } \\
\hline & 0 & $1-3$ & $4-6$ & $7-9$ & 10 \\
\hline \multicolumn{6}{|l|}{$\%$ distribution } \\
\hline None & & 26.32 & 47.37 & 15.79 & 10.53 \\
\hline Once a month or less & & & 30 & 40 & 30 \\
\hline $2-4$ times a month & & & 28.57 & 71.43 & \\
\hline $2-3$ times a week & & & & 66.7 & 3.33 \\
\hline \multirow[t]{3}{*}{4 times a week or more } & & & & 37.5 & 62.5 \\
\hline & \multicolumn{5}{|c|}{ Proportion of Free Time Spent with Peers Who Regularly Use Drugs $(0-10)$} \\
\hline & 0 & $1-3$ & $4-6$ & $7-9$ & 10 \\
\hline \multicolumn{6}{|l|}{$\%$ distribution } \\
\hline None & 21.05 & 47.37 & 10.53 & 15.79 & 5.26 \\
\hline Once a month or less & & 30 & 40 & 30 & \\
\hline $2-4$ times a month & & 28.57 & 14.29 & 57.14 & \\
\hline $2-3$ times a week & & 33.3 & 16.67 & 33.3 & 16.67 \\
\hline 4 times a week or more & & & & 50 & 50 \\
\hline
\end{tabular}

A weak to moderate positive correlation was shown to exist between the expected frequency illicit drug use and the three peer context factors. A statistically significant, yet weak positive correlation was shown between the expected frequency of illicit drug use and the proportion of friends who approved of drug use, $r(50)=.472, p$ $<.001$. In contrast to Table 2, there were no students who expected not to use drugs, yet reported that all of their friends disapproved of illicit drug use: in fact, $10.53 \%$ of them had friends who all approved of drug use. A large portion of students who reported higher rates of expected illicit drug use had a high proportion of friends who approved of drug use: $33.3 \%$ of students who expected to use illicit drugs $2-3$ times a week and $62.5 \%$ of respondents who expected to use 4 times or more a week said all of their friends approved of illicit drug use.

A statistically significant, moderate positive correlation was found between the expected frequency of illicit drug use and the proportion of friends who regularly used drugs, $r(50)=.609, p<.001$. Here, only students who expected to use illicit drugs 2-3 times a week and 4 times a week or more had friends who all regularly used drugs, $16.67 \%$, and $25 \%$, respectively. As in the trends from Table 2, most students who did not expect to use drugs had no or nearly no friends who regularly used drugs, $21.05 \%$, and $42.11 \%$, respectively. Interestingly, $70 \%$ of students who expected to use illicit drugs once a month said that nearly all their friends regularly used drugs. No group other than students who did not expect to use illicit drugs said that they had no friends who regularly used drugs.

In addition, a statistically significant, moderate positive correlation existed between the expected frequency of illicit drug use and the proportion of free time spent around friends who regularly used drugs, $r(50)=.621, p$ $<.001$. Students who expected to use illicit drugs 4 times a week or more reported spending their free time almost exclusively around peers who regularly used drugs. Students who did not expect to use illicit drugs 4 times a week or more but still used illicit drugs were split between spending little time around drugs using friends and spending nearly all of their time around peers who regularly used drugs.

Associations found in Table 3, being positive and statistically significant, further undermine the null hypothesis. 
There was a moderate positive correlation between peer context factors and expected illicit drug use. Results from Table 3 support the hypothesis, demonstrating a statistically significant positive correlation between an increase in peer context factors and a decrease in expected illicit drug use.

\subsubsection{Major Trends 2}

Much as in the previous section, this section proposes two hypotheses for Tables 4 and 5 that may explain the correlations between the expected frequency of licit and illicit drug use and the perception of punishment severity and likelihood.

Hypothesis

- The hypothesis posits that the deterrence theory is ineffective in producing a deterrence effect in the studied sample. The hypothesis states there will either be a positive correlation or no correlation between adolescent drug use and severity and likelihood of punishment. The hypothesis will hold if the frequency of drug use increases with an increasing perception of punishment severity and likelihood, or if no trend exists. The hypothesis is supported by the following findings in literature: there is a lack of social control in place to inhibit adolescents' inherent deviant impulse; adolescents' ability to make rational decisions is impaired by their lack of brain impulse controls; adolescents disproportionately focus on rewards rather than risks in the presence of peers; adolescents use drugs as a creative choice of resistance against school in line with their counter-school identity.

Null hypothesis

- The null hypothesis assumes that policies under the theory of deterrence are effective in deterring drug use generally in the studied sample. The null hypothesis states that a negative correlation between adolescent drug use and both severity and likelihood of punishment will exist. The null hypothesis will stand if the frequency of drug use decreases with an increasing perception of punishment severity and likelihood. The null hypothesis is assumed to be true when consistent with the principles of the theory of deterrence: humans are self-interested beings that will make rational decisions for the best-benefit outcome; the more severe the punishment, the lesser the crime rate; the more certain the punishment, the lesser the crime rate. Some evidence from the literature suggests adolescents are capable of rational thinking with similar capabilities to adults, therefore the desired rational deterrence effect of policies following the deterrence theory will support the null hypothesis.

Table 4. Correlation between expected frequency of licit drug use and punishment severity and likelihood

\begin{tabular}{|c|c|c|c|c|c|}
\hline \multirow[b]{2}{*}{ Expected Use } & \multicolumn{5}{|c|}{ Perception of Punishment Severity } \\
\hline & 0 & $1-3$ & $4-6$ & $7-9$ & 10 \\
\hline \multicolumn{6}{|l|}{$\%$ distribution } \\
\hline None $(n=16)$ & & 6.25 & 31.25 & 62.5 & \\
\hline Once a month or less $(n=10)$ & & & 20 & 80 & \\
\hline $2-4$ times a month $(n=8)$ & & 37.5 & 12.5 & 50 & \\
\hline $2-3$ times a week $(n=6)$ & & & & 50 & 50 \\
\hline \multirow[t]{3}{*}{4 times a week or more $(n=10)$} & & & 30 & 40 & 30 \\
\hline & \multicolumn{5}{|c|}{ Perception of Punishment Likelihood } \\
\hline & 0 & $1-3$ & $4-6$ & $7-9$ & 10 \\
\hline \multicolumn{6}{|l|}{$\%$ distribution } \\
\hline None & & 37.5 & 37.5 & 25 & \\
\hline Once a month or less & & 20 & 30 & 50 & \\
\hline 2-4 times a month & 25 & 37.5 & & 37.5 & \\
\hline $2-3$ times a week & & 16.67 & 50 & 16.67 & 16.67 \\
\hline 4 times a week or more & & 10 & 60 & 20 & 10 \\
\hline
\end{tabular}

For both punishment severity and likelihood variables, a positive (albeit very weak correlation) existed between perceptions of punishment severity and likelihood and expected frequency of licit drug use. There existed a statistically insignificant, very weak positive correlation between the expected frequency of licit drug use and perception of punishment severity, $\mathrm{r}(50)=0.202$. No students, regardless of their expected licit drug use, found that their school policy punishment had zero severity. All students replied that their school policy punishment was on the severe side, more severe than necessary, or extremely severe. All students who expected to use licit drugs 2-3 times a week replied that their school policy punishment was more severe than necessary or extremely severe 
$(50 \%, 50 \%): 30 \%$ of students who used licit drugs 4 or more times a week rated their school policy punishment to be " 10 " as in extremely severe.

Furthermore, there existed a statistically insignificant, very weak positive correlation between the expected frequency of student licit drug use and student perception of punishment likelihood, r (50) $=0.106 .10 \%$ of students who expected to use licit drugs 4 or more times a week believed they would certainly be caught, while $25 \%$ of students who expected to use licit drugs 2-4 times a month believed there was zero chance of them getting caught. Students who did not expect to use licit drugs were split evenly between believing the punishment was not severe enough and on the severe side, $37.5 \%$, and $37.5 \%$. Only $16.67 \%$ and $10 \%$ of students who expected to use licit drugs 2-3 times a week and 4 times a week or more, respectively, marked their chances of being caught as certain (10).

The associations demonstrated in Table 4, being positive and statistically insignificant, reject the null hypothesis. There was no discernible correlation between an increase in perceptions of punishment severity and likelihood and a decrease in expected frequency of licit drug use. A very weak argument could be made that the expected frequency of licit drug use is positively correlated with punishment severity and likelihood, but the two relevant correlations fail the statistical significance test $(p>.05)$. Results from Table 4 support the hypothesis, as no statistically significant correlation exists between increase in both punishment severity and likelihood and decrease in expected frequency licit drug use.

Table 5. Correlation between expected frequency of illicit drug use and punishment severity and likelihood

\begin{tabular}{|c|c|c|c|c|c|}
\hline \multirow[b]{2}{*}{ Expected Use } & \multicolumn{5}{|c|}{ Perception of Punishment Severity } \\
\hline & 0 & $1-3$ & $4-6$ & $7-9$ & 10 \\
\hline \multicolumn{6}{|l|}{$\%$ distribution } \\
\hline None $(n=19)$ & & 5.26 & 31.58 & 63.16 & \\
\hline Once a month or less $(n=10)$ & & & 10 & 90 & \\
\hline $2-4$ times a month $(n=7)$ & & 42.86 & & 42.86 & 14.29 \\
\hline $2-3$ times a week $(n=6)$ & & & 33.3 & 33.3 & 33.3 \\
\hline \multirow[t]{3}{*}{4 times a week or more $(n=8)$} & & & 25 & 37.5 & 37.5 \\
\hline & \multicolumn{5}{|c|}{ Perception of Punishment Likelihood } \\
\hline & 0 & $1-3$ & $4-6$ & $7-9$ & 10 \\
\hline \multicolumn{6}{|l|}{$\%$ distribution } \\
\hline None & & 36.84 & 36.84 & 26.32 & \\
\hline Once a month or less & & 10 & 20 & 70 & \\
\hline $2-4$ times a month & 28.57 & 28.57 & 42.86 & & \\
\hline $2-3$ times a week & & 33.3 & 33.3 & 16.67 & 16.67 \\
\hline 4 times a week or more & & 12.5 & 50 & 25 & 12.5 \\
\hline
\end{tabular}

Consistent with Table 4, in Table 5 the correlation between expected frequency of illicit drug use and perceptions of punishment severity and likelihood was positive and very weak. There existed a statistically insignificant, very weak positive correlation between the frequency of student expected illicit drug use and student perception of punishment severity, $r(50)=0.133$. As in Table 4, no students out of 50 perceived the punishment to have zero severity, and the students who expected to use illicit drugs largely believed the punishment was more severe than necessary or extremely severe.

In addition, there existed a statistically insignificant, very weak positive correlation between the expected frequency of student illicit drug use and student perception of punishment likelihood, $r(50)=0.044$. There was virtually no correlation between the expected frequency of illicit drug use and student perception of punishment likelihood. $37.5 \%$ of students who expected to use illicit drugs 4 or more times a week believed they were at a very high or at a certain risk of getting caught. Interestingly, $70 \%$ of students who expected to use illicit drugs once a month also believed that they were at a very high risk of getting caught: the largest distribution of students among any other group to perceive likelihood of punishment to be very high.

The correlations demonstrated in Table 5, being positive and statistically insignificant, contradict the null hypothesis. There was no strong negative association between student illicit drug use and student perception of punishment severity and likelihood that the null hypothesis assumed. A weak argument could be made that the expected frequency of illicit drug use is positively correlated with punishment severity and likelihood: however, the two relevant correlations fail the statistical significance test $(p>.05)$. Instead, analysis of Table 5 supports the hypothesis, as no statistically significant correlation exists between increase in punishment severity and likelihood 
and decrease in expected frequency of illicit drug use.

\section{Discussion}

This study does not find increasing severity and likelihood of school drug and alcohol policy punishments to be linked with a decrease in student drug use: on the contrary, students who used drugs most heavily seemed to perceive punishment severity and likelihood to be slightly higher. Instead, this study finds compelling evidence that frequency of student drug use is closely associated with student exposure to contextual peer influence factors. In this section, the findings from results will be discussed in greater detail and placed in still more explicit relation to previous research.

Generally, adolescent drug use was found to be highly dependent on grade level and day or boarding status. Students were more likely to use licit or illicit drugs as their grade level increased, and students in the junior grade level were found to use drugs most frequently. The 2019 national MTF survey corroborates the increase in drug use along grade lines: $25.5 \%$ of 12 th graders vaped nicotine in the previous month, followed by 10 th graders at $19.9 \%$ and 8 th graders at $9.6 \%$ (U.S. Department of Health and Human Services, 2019). Boarding students were found to use drugs more frequently in the previous month compared to day students. No day students who used drugs were able to use both licit and illicit drugs as heavily as boarding students of the same grade, suggesting that boarding students were less inhibited by social controls like parents, and that high accessibility to peers might increase drug use. The absence or inadequacy of parental monitoring has been associated with an increase in adolescent drug use (Dorius et al., 2004). Due to the significant physical barriers placed between boarding students and their parents, adolescents may not act out of conformity because they feel no need to conform to appease their parents (Dorius et al., 2004). In a similar light, for some adolescents, conformity to school might be less important than conformity to parents. Combined with the lack of parental monitoring and connection that has proven to reduce peer influence, adolescents living in dormitories with or alongside peers have more opportunities to engage in intimate peer groups where deviant behavior is observed, practiced, and reinforced (Hirschi, 1969). Consequently, lower rates of drug use among day students may be symptomatic of their physical distance from parents and peers.

Of the two major trends this study identified on, major trend 1 affirmed the hypothesis since a moderate to strong positive correlation was shown between adolescent drug use and peer context factors. A moderate positive correlation was found between expected frequency of student licit and illicit drug use and proportion of student friends who regularly used drugs, and proportion of student friends who approved of drug use. The positive correlation between expected frequency of student licit drug use and proportion of free time spent with peers who regularly used drugs was the strongest $(r=.718)$; the same correlation for illicit drug use was slightly weaker $(r$ $=.621$ ). Social learning theory provides supporting evidence for this association, with findings backing the theory establishing that intimate peer groups create an environment where social deviances like drug use are observed, practiced, and reinforced (Hirschi, 1969; Reed \& Roundtree, 1997). Adolescents whose friends largely use drugs and advocate drug use may be exposed more frequently to situations where social drug use is rewarded and celebrated among peers: the more complete this echo-chamber, the higher the proportion of their friends approve of drug use. Steinberg (2008) claims adolescents in the presence of peers are especially susceptible to focusing on rewards rather than risks: suggesting a higher score on the peer context factors indicates higher exposure to circumstances where rational thinking is suppressed. Furthermore, Steinberg (2008) also finds adolescents to have underdeveloped brain regions that moderate impulse control, raising the possibility that impulsive decision-making may further aggravate adolescents' narrow focus on rewards. While the causality of these correlations cannot be conclusively demonstrated, findings from the adolescent risk-taking theory and neurobiological research provide compelling evidence suggesting the role of peer context factors in facilitating adolescent drug use.

The link between the proportion of student friends who approve of drug use and frequency of drug use is especially concerning. Adolescents value the opinions of peers and their social standing among peers more than any other age group, and the general approval of drug use among friends may take priority over the disapproval of drug use by school or the broader society. Past research found adolescents who used marijuana in social circumstances developed positive cognitive definitions about marijuana and about future social marijuana use (Petraitis et al., 1996). Popular peer approval of drugs might, in a similar way, cause adolescents to define drug use positively and expect positive outcomes in future social drug-using sessions. In this study, illicit drugs were approved by a larger proportion of peers across the independent variable when compared to proportions of peers who approved licit drugs. The recent decriminalization and legalization of marijuana in many states (though not legalized in Connecticut) is thought to have contributed to the disparity between licit drug approval and illicit drug approval. 
Major trend 2 positively (but weakly) correlated punishment severity and likelihood with expected frequency student drug use. All correlations were statistically insignificant and suggested a weak trend: no correlations were found across the board. The direct relationship between zero-tolerance policies and problem behaviors remains significantly understudied. However, Curran (2016) provides evidence from a nationwide review of zero tolerance that finds zero-tolerance policies to not reduce perceptions of problem behavior among school principals. Contrary to popular presumptions, students who used licit and illicit drugs heavily said they viewed school policies to be highly severe and punishment to be highly certain. Student perceptions of punishment severity and likelihood did not vary widely by their expected frequency of drug use. If perceptions of punishment had been universal and not varied individually, stronger correlations may have been found, yet even such assumptions cannot explain why students who used drugs 2-3 times a week or 4 times a week or more perceived their school policy punishment to be more severe and likely than any other group.

There is the possibility that some students were deterred by the high severity and likelihood of punishment, and only groups of students "immune" to consequences continued heavy drug use (while fully aware of the stakes). Past studies on student counter-school culture confirmed the occurrence of these immune student groups, discovering that students marginalized from school used drugs as a creative means of "mellow resistance" against the school (Fletcher et al., 2009). Indeed, some students in this study may use drugs because they genuinely disrespect the school's highly punitive punishments for infractions. However, it might equally be the case that a zero-tolerance policy with harsh punishments is not effective at reducing problem behavior. Being suspended or expelled might not be the best-benefit outcome for adolescents in the long run, but in the context of peer influence, results from this study suggest immediate social rewards take precedence over school consequences, regardless of severity or likelihood.

There are several limitations to this study. First, using cross-sectional data that is not longitudinal or derived from a controlled setting, this study does not demonstrate causality behind correlations. The correlations themselves show peer context factors to increase with frequency of student drug use but soliciting peer context factors as a direct cause to an increase or decrease in student drug use frequency would require a longitudinal approach.

Second, the sample size is limited to 50 students. There is a chance that anomalies have skewed the results of the observed trends somewhat. The sample group is also geographically specific: respondents are largely private school students bound to the state of Connecticut (other states might hold substances differently accountable), and findings from this study may not be recreated in alternate regions and demographics.

Third, grade level remains a strong predictor of student drug use, as does boarding student or day-student status. More accurate results surrounding peer contexts and punishment severity and likelihood could be drawn if future studies separate data by grade level or occupational status. The separation of data, inherently requiring a larger data pool, may account for such preconditioned trends that may skew results.

Finally, all data were gathered through a student self-reported survey. While accurate and honest measures of student drug use are difficult to collect without student cooperation, school punishment severity and likelihood could be ascertained without relying on student perceptions. There are a few reasons why student perceptions may be an inaccurate measure of punishment severity or likelihood: misconceptions about school policy, personal experiences with the school disciplinary system, or exaggerating perceptions. A more systematic approach would be taken to rate school policy and its punishments on some standard metric, through questioning administrators or by self-conducting policy analysis. This effort, again, would require a large-scale study with broader state-wide or national scope.

\section{Conclusion}

Despite growing evidence that condemns the negative effects of punitive and exclusionary discipline, Zero-tolerance policies remain an integral part of school discipline., Few studies have attempted to estimate the efficiency of zero tolerance in reducing problem behaviors; however, the general deterring effect of zero tolerance has been refuted by at least one study (Curran, 2016), and results from this paper corroborates those results. This paper elaborates on a body of literature that questions the efficiency of zero tolerance in reducing problem behavior, focusing on studies that find contextual factors like peers and adolescent neurobiological characteristics that directly challenge the theory of deterrence. This paper aimed to determine if factors that predicted peer influence held stronger authority over adolescent drug use compared to policies that follow deterrence theory.

As a whole, the results of this study suggest perceptions of punishment to be unrelated to adolescent drug use but finds factors that predict student interaction with drug-using or drug-approving peers to be strongly correlated with drug use. Student drug use could be predicted quite accurately from their interaction with drug-using or drug-approving peers: while perceptions of school drug and alcohol policy punishments varied randomly with no 
strong pattern among students. Despite strong evidence that peers hold powerful control over adolescent behavior, prior research failed to investigate the extent to which peers determine deviant behavior like drug abuse. This study endorses the possibility that peer influence supersedes deterring measures at least in terms of adolescent drug use.

Results from this study provide initial evidence that contextual factors, peer influence or otherwise, might override principles of deterrence theory in drug and alcohol discipline. Such evidence provides crucial grounds for practices revising deterrence theory, like zero tolerance, with consideration of the persuasive influence of peer adolescents, and the limits of rational deterrence in adolescents. In this way, results of this study encourage future researchers in zero-tolerance discipline and adolescent drug abuse to broaden the scope of their inquiry and include various real-world contextual factors that mitigate the effectiveness of school discipline.

\section{References}

American Psychological Association Zero Tolerance Task Force. (2008, December 1). Are Zero Tolerance Policies Effective in the Schools? An Evidentiary Review and Recommendations. American Psychologist, 63(9), 852-862. https://doi.org/10.1037/0003-066X.63.9.852

Arcia, E. (2006). Achievement and enrollment status of suspended students: Outcomes in a large, multicultural school district. Education and Urban Society, 38, 359-369. https://doi.org/10.1177/0013124506286947

Beccaria, C. (2009). On crimes and punishments. Seven Treasures.

Bentham, J., Burns, J. H., \& Hart, H. L. A. (1982). An introduction to the principles of morals and legislation. Methuen.

Bronfenbrenner, U., \& Morris, P. A. (2006). The Bioecological Model of Human Development. In W. Damon \& R. M. Lemer (Eds.), Handbook of Child Psychology: Theoretical Models of Human Development (pp. 793-828). John Wiley \& Sons Inc. https://doi.org/10.1002/9780470147658.chpsy0114

Costenbader, V., \& Markson, S. (1998). School suspension: A study with secondary school students. Journal of School Psychology, 36, 59-82. https://doi.org/10.1016/S0022-4405(97)00050-2

Curran, F. (2016). Estimating the Effect of State Zero Tolerance Laws on Exclusionary Discipline, Racial Discipline Gaps, and Student Behavior. Educational Evaluation and Policy Analysis, 38(4), 658-660. https://doi.org/10.3102/0162373716652728

Dorius, C., Bahr, S., Hoffmann, J., \& Harmon, E. (2004). Parenting Practices as Moderators of the Relationship between Peers and Adolescent Marijuana Use. Journal of Marriage and Family, 66(1), 163-178. https://doi.org/10.1111/j.0022-2445.2004.00011.x-i1

Education Week. (2018, September 5). Connecticut Earns a B on State Report Card, Ranks Third in Nation. Editorial Projects in Education, 37(17).

Ellickson, P. L., Tucker, J. S., Klein, D. J., \& Saner, H. (2004). Antecedents and outcomes of marijuana use initiation during adolescence. Preventive Medicine, 39(5), 976-984. https://doi.org/10.1016/j.ypmed.2004.04.013

Elliott, D. S., Wilson, W. J., Huizinga, D., Sampson, R. J., Elliott, A., \& Rankin, B. (1996). The effects of neighborhood disadvantage on adolescent development. Journal of Research in Crime and Delinquency, 33(4), 389-426. https://doi.org/10.1177/0022427896033004002

Finn, K. (2012). Marijuana Use at School and Achievement-Linked Behaviors. The High School Journal, 95(3), 3-13. https://doi.org/10.1353/hsj.2012.0005

Fletcher, A., Bonell, C., \& Rhodes, T. (2009). New Counter-School Cultures: Female Students' Drug Use at a High-Achieving Secondary School. British Journal of Sociology of Education, 30(5), 549-562. https://doi.org/10.1080/01425690903101049

Gardner, M., \& Steinberg, L. (2005). Peer influence on risk taking, risk preference, and risky decision making in adolescence and adulthood: An experimental study. Developmental Psychology, 41, 625-635. https://doi.org/10.1037/0012-1649.41.4.625

Gibbs, J. P. (1968). Crime, Punishment and Deterrence. Southwestern Social Science Quarterly, 48, 515-530.

Hirschi, T. (1969). Causes of delinquency. Berkeley: University of California Press.

Hoffman, S. (2014). Zero Benefit: Estimating the Effect of Zero Tolerance Discipline Policies on Racial Disparities in School Discipline. Educational Policy, 28, 65-100. https://doi.org/10.1177/0895904812453999 
Hoffmann, J. (2002). The Community Context of Family Structure and Adolescent Drug Use. Journal of Marriage and Family, 64(2), 314-330. https://doi.org/10.1111/j.1741-3737.2002.00314.x

Kennedy, D. M. (2010). Deterrence and crime prevention. Routledge.

Luthar, S. S., Small, P. J., \& Ciciolla, L. (2018). Adolescents from upper middle class communities: Substance misuse and addiction across early adulthood. Development and Psychopathology, 30(1), 315-335. https://doi.org/10.1017/S0954579417000645

Maag, J. W. (2001). Reward by punishment: reflections on the disuse of positive reinforcement in schools. The Council for Exceptional Children, 67(2), 173-186. https://doi.org/10.1177/001440290106700203

Martinez, S. (2009). A System Gone Berserk: How Are Zero-tolerance Policies Really Affecting schools? Preventing School Failure, 53(4), 153-158. https://doi.org/10.3200/PSFL.53.3.153-158

Morrison, G. M., \& Skiba, R. (2001). Predicting violence from school misbehavior: Promises and perils. Psychology in the Schools, 38(2), 173-184. https://doi.org/10.1002/pits.1008

Nagin, D. (1998). Criminal Deterrence Research at the Outset of the Twenty-First Century. Crime and Justice, 23, 1-42. https://doi.org/10.1086/449268

Pathammavong, R., Leatherdale, S. T., Ahmed, R., Griffith, J., Nowatzki, J., \& Manske, S. (2011). Examining the link between education related outcomes and student health risk behaviours among Canadian youth: Data from the 2006 National Youth Smoking Survey. Canadian Journal of Education, 34(1), 215-247. Retrieved August 1, 2020, from http://www.jstor.org/stable/canajeducrevucan.34.1.215

Pauwels, L., Weerman, F., Bruinsma, G., \& Bernasco, W. (2011). Perceived sanction risk, individual propensity and adolescent offending: Assessing key findings from the deterrence literature in a Dutch sample. European Journal of Criminology, 8(5), 386-400. https://doi.org/10.1177/1477370811415762

Petraitis, J., Flay, B. R., \& Miller, T. Q. (1995). Reviewing theories of adolescent substance use: Organizing pieces in the puzzle. Psychological Bulletin, 117, 67-86. https://doi.org/10.1037/0033-2909.117.1.67

Raffaele Mendez, L. M. (2003). Predictors of Suspension and Negative School Outcomes: A longitudinal Investigation. New Directions for Youth Development, 99, 19-35. https://doi.org/10.1002/yd.52

Reed, M. D., \& Rountree, P. W. (1997). Peer pressure and adolescent substance abuse. Journal of Quantitative Criminology, 13, 143-180. https://doi.org/10.1007/BF02221306

Reyna, V. F., \& Farley, F. (2006). Risk and rationality in adolescent decision making: Implications for theory, practice, and public policy. Psychological Science in the Public Interest, 7, 1-44. https://doi.org/10.1111/j.1529-1006.2006.00026.x

Steinberg L. (2008). A Social Neuroscience Perspective on Adolescent Risk-Taking. Developmental Review: DR, 28(1), 78-106. https://doi.org/10.1016/j.dr.2007.08.002

U.S. Commissioner of Education Statistics. (1998, March 18). Violence and Discipline Problems in U.S. Public Schools: 1996-1997. National Center for Education Statistics. Retrieved from https://nces.ed.gov/pressrelease/violence.asp

U.S. Department of Education Office for Civil Rights. (2014). Civil Rights Data Collection- Data snapshot: School discipline (Issue Brief No. 1). Retrieved from http://ocrdata.ed.gov/Downloads/CRDC-School-Discipline-Snapshot.pdf

U.S. Department of Health and Human Services. (2019, December 18). Monitoring the Future 2019 Survey Results: Overall Findings. National Institute on Drug Abuse. Retrieved from https://www.drugabuse.gov/drug-topics/trends-statistics/infographics/monitoring-future-2019-survey-result s-overall-findings

Zimring, F. E., Hawkins, G. J., \& Gorenberg, J. (1976). Deterrence: The legal threat in crime control. University of Chicago Press.

\section{Copyrights}

Copyright for this article is retained by the author, with first publication rights granted to the journal.

This is an open-access article distributed under the terms and conditions of the Creative Commons Attribution license (http://creativecommons.org/licenses/by/4.0/). 